The Role of Mitochondrial Dysfunction in Radiation-Induced
Heart Disease: From Bench to
Bedside

\author{
Katie Livingston ${ }^{1,2}$, Rachel A. Schlaak ${ }^{2,3}$, Lindsay L. Puckett ${ }^{1,2}$ and Carmen Bergom ${ }^{1,2,4 *}$ \\ ${ }^{1}$ Department of Radiation Oncology, Medical College of Wisconsin, Milwaukee, WI, United States, ${ }^{2}$ Cancer Center, Medical \\ College of Wisconsin, Milwaukee, WI, United States, ${ }^{3}$ Department of Pharmacology \& Toxicology, Medical College of \\ Wisconsin, Milwaukee, WI, United States, ${ }^{4}$ Cardiovascular Center, Medical College of Wisconsin, Milwaukee, WI, \\ United States
}

Radiation is a key modality in the treatment of many cancers; however, it can also affect normal tissues adjacent to the tumor, leading to toxic effects. Radiation to the thoracic region, such as that received as part of treatment for breast and lung cancer, can result in incidental dose to the heart, leading to cardiac dysfunction, such as pericarditis, coronary artery disease, ischemic heart disease, conduction defects, and valvular dysfunction. The underlying mechanisms for these morbidities

OPEN ACCESS

Edited by:

Canan G. Nebigil,

École supérieure de biotechnologie Strasbourg (ESBS), France

Reviewed by:

Guido laccarino,

University of Naples Federico II, Italy Ariane Vieira Scarlatelli Macedo, Santa Casa of Sâo Paulo, Brazil

*Correspondence:

Carmen Bergom cbergom@mcw.edu

Specialty section:

This article was submitted to Cardio-Oncology,

a section of the journal

Frontiers in Cardiovascular Medicine

Received: 15 December 2019 Accepted: 05 February 2020 Published: 21 February 2020

Citation:

Livingston K, Schlaak RA, Puckett LL and Bergom C (2020) The Role of Mitochondrial Dysfunction in Radiation-Induced Heart Disease:

From Bench to Bedside.

Front. Cardiovasc. Med. 7:20 doi: 10.3389/fcvm.2020.00020 are currently being studied but are not entirely understood. There has been increasing focus on the role of radiation-induced mitochondrial dysfunction and the ensuing impact on various cardiac functions in both preclinical models and in humans. Cardiomyocyte mitochondria are critical to cardiac function, and mitochondria make up a substantial part of a cardiomyocyte's volume. Mitochondrial dysfunction can also alter other cell types in the heart. This review summarizes several factors related to radiation-induced mitochondrial dysfunction in cardiomyocytes and endothelial cells. These factors include mitochondrial DNA mutations, oxidative stress, alterations in various mitochondrial function-related transcription factors, and apoptosis. Through improved understanding of mitochondria-dependent mechanisms of radiation-induced heart dysfunction, potential therapeutic targets can be developed to assist in prevention and treatment of radiation-induced heart damage.

Keywords: mitochondria, radiation-adverse effects, radiation-induced cardiovascular toxicity, oxidative stress, radiation, cardiomyocyte, endothelial cell, apoptosis

\section{RADIATION-INDUCED CARDIAC DISEASE}

It has long been recognized that high-dose radiation exposure to the heart can cause cardiac dysfunction, manifesting months to decades following treatment. In 1924, radiation-induced histologic changes to the heart were first reported following radiation treatment of a patient for Hodgkin's lymphoma (1). Since that time, it has been established that therapeutic radiation to the thoracic region, for treatment of lymphomas, breast and lung cancers and pediatric malignancies can cause cardiac injuries (2). Even low doses of radiation can lead to radiation-induced heart dysfunction (RIHD), as demonstrated in epidemiologic cohorts of atomic bombing survivors and occupational exposures $(1,3,4)$. Radiation can cause various structural changes to cardiac 
tissue, including the cardiac vasculature, leading to complications, such as pericarditis, coronary artery disease, ischemic heart disease, congestive heart failure, conduction defects and valvular dysfunction $(5,6)$.

Darby et al. completed a population-based case-control study of women who underwent radiotherapy for breast cancer. In this study, for every gray (Gy) of mean dose to the heart (the average mean dose was $4.9 \mathrm{~Gy}$ ), the rate of major coronary events (myocardial infarction, coronary revascularization, or death from ischemic cardiac disease) increased by $7.4 \%$ with no upper limit. Cardiac events occurred within the first 5 years and continued several decades post-radiotherapy (7). Other studies have also examined the association between mean heart dose and cardiac events/disease, finding an $\sim 4-16 \%$ increased risk per Gy of mean heart dose (7-9). Studies have also suggested RIHD can occur in non-small cell lung cancer patients within 2 years post-radiation exposure (8-11). In a number of lung cancer studies, mortality rates were cardiac dose-dependent, either based on mean heart dose (12) or with the percent of heart receiving 5 Gy (13), 30 Gy (13), or $50 \mathrm{~Gy}(10)$. In pediatric and young adult cancer patients who received cardiac radiation, there is over a 6 -fold relative risk of RIHD, defined as congestive heart failure, myocardial infarction, pericardial disease, and/or valvular abnormalities (14). Cardiac events were also found to be dose-dependent, with the highest risk of events found when the mean heart dose was $>30$ Gy (15).

As demonstrated from these studies, cardiac exposure should be minimized when possible for radiation therapy to the thoracic region. There have been many advances in reducing cardiac exposure by improving both imaging and radiotherapy techniques (16-21). However, heart radiation exposure often remains unavoidable. There are currently no widely used methods to reverse RIHD, thus the primary way to reduce cardiotoxicity is through improved treatment planning. There is a need for preclinical studies to understand radiationinduced changes on a cellular and molecular level, with the hope of discovering new targetable pathways. Currently, there are several hypotheses on the predominant causes of RIHD, with most identified using animal models. One cause is the formation of fibrosis, distinguished by collagen deposition in and surrounding cardiomyocytes (1, 6, 22). An additional cause is macrovascular and microvascular injury, developed in a multifactorial manner by endothelial cell damage and adhesion, and activation of inflammatory and atherosclerotic responses (1, 6, 23-28). Signaling pathways, including apoptosis and mitochondrial dysfunction, have also been linked to RIHD $(29,30)$. This review will focus on the role of radiationinduced mitochondrial dysfunction in RIHD. The biologic pathways described in this review are illustrated in Figure 1, and the discussed clinical and preclinical studies are summarized in Table 1.

\section{MITOCHONDRIA AND OXIDATIVE STRESS}

The role of cardiomyocyte mitochondria is critical to cardiac function, with each cardiomyocyte having abundant mitochondria that make up $\sim 30 \%$ of cell volume $(43,44)$. Mitochondria have a role in stress responses, cell death, and metabolic processes. They are essential for energy production, which is created by products of glycolysis and fatty acid metabolism via oxidative phosphorylation in the respiratory chain, yielding reactive oxygen species (ROS) biproducts, such as superoxide, peroxide and hydroxyl radicals. Wang et al. reviewed the normal mitochondrial mechanisms, as well as manners in which equilibrium can be interrupted in the heart after radiation. In homeostasis, ROS facilitate cellular functions, including immune responses, signal transduction and apoptosis. ROS can be neutralized by antioxidants when their concentrations are in excess (29). If this highly regulated process is disrupted, increased production or decreased removal of ROS can lead to cellular and DNA damage (29).

Stress-induced mitochondrial damage can cause a loss of mitochondrial membrane potential, leading to the mitochondria undergoing either fission or fusion. Fission helps mitigate stress by fusing parts of damaged mitochondria with normal mitochondria and is regulated by proteins including Opa1 and Mitofusin-1 and-2 (Mfn-1 and Mfn-2). Fission is needed to help create new mitochondria, but also serves as quality control through facilitating apoptosis during high levels of cellular stress. Fission is mediated by proteins including Drp1 and Mft (45, 46). If damaged mitochondria need to be eliminated, kinase PINK1 yields as a sensor of mitochondrial damage and signals to induce mitophagy (46). These complex dynamic mitochondrial processes are imperative in cardiomyocytes, as these cells obtain more than $90 \%$ of their energy from mitochondrial respiration $(35,40)$. This makes mitochondria within these energy-demanding cells an ideal study model to characterize mitochondrial changes that occur after radiation exposure.

It was discovered in the late 1960s that radiation can drastically alter the structural appearance of mitochondria, both short- and long-term. Seven years after high dose radiation ( $52 \mathrm{~Gy}$ ) to the mediastinal region in a human patient, electron microscopy revealed cardiomyocyte mitochondria that were variably swollen with decreased number and disorganization of cristae, often with fused outer double membranes (31). Changes in mitochondrial structural integrity occurred as early as $48 \mathrm{~h}$ following exposure in rabbit myocardial cells which had received a single dose of either 10 or $13 \mathrm{~Gy}$ (32). These findings have led to additional studies on the role of mitochondrial function in RIHD.

On a molecular level, ionizing radiation directly modifies DNA, including single- and double-stranded breaks, base damage, and cross-links, all of which can lead to cell death if not repaired properly. Indirectly, radiation can lead to ROS formation, which can cause cellular stress and death (1). Mitochondrial DNA (mtDNA) is a major radiation target because it lacks the protective effects of histones (47). In addition, it is generally repaired less efficiently than nuclear DNA (48) and has a mutation rate 10-1,000 times higher than nuclear DNA, making it an ideal model to study the mutational effects of radiation $(33,48,49)$. This has been most notably reflected with the mutation called common deletiona 4,977 base pair deletion within mtDNA that has become a marker for oxidative damage. Increased levels of the common 


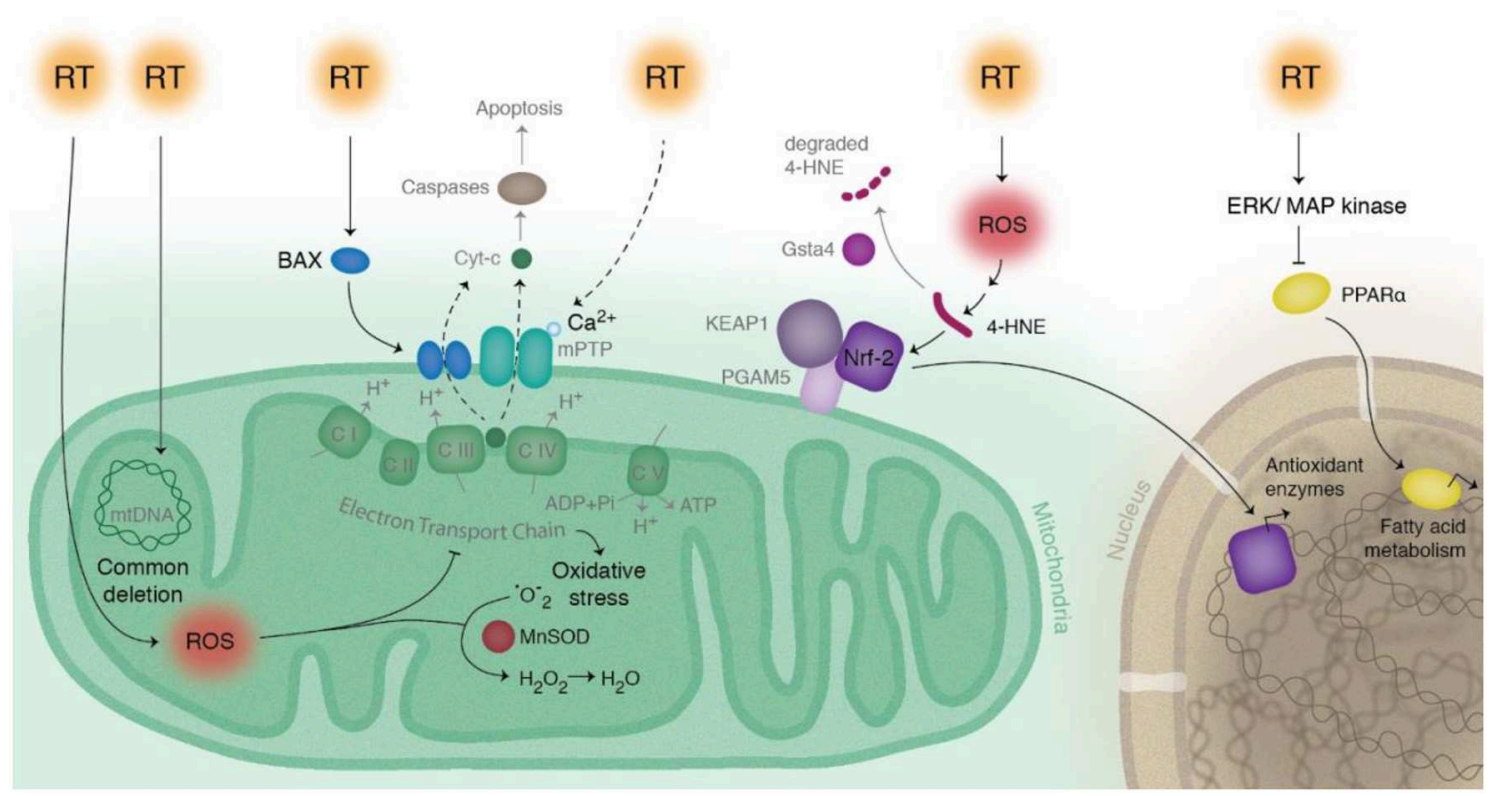

FIGURE 1 | Schematic of radiation-induced effects on pathways related to mitochondria in cardiac cells. Radiation therapy (RT) directly modifies mitochondrial DNA, as seen most notably with the common deletion mutation. RT also indirectly modifies mitochondrial dysfunction by production of reactive oxygen species (ROS), leading to a disruption in the electron transport chain and increased levels of 4-HNE and increased production of antioxidant enzymes via Nrf2. Manganese superoxide dismutase (MnSOD) decreases ROS concentrations by converting superoxide $\left(\mathrm{O}_{2}^{-}\right)$to hydrogen peroxide $\left(\mathrm{H}_{2} \mathrm{O}_{2}\right)$. RT decreases fatty acid energy production via activation of ERK/MAP kinase pathway, which inhibits PPAR- $\alpha$. RT causes activation of Bax and release of cytochrome $c$, initiating the intrinsic pathway of apoptosis.

deletion have been noted in human cardiac cells undergoing oxidative stress secondary to atrial fibrillation (50). Other studies have noted radiation-induced development of common deletion within human cell lines, both in low $(0.1 \mathrm{~Gy})$ and therapeutic doses (>1 Gy) $(33,48,51)$, although no studies to date have specifically analyzed radiation-induced common deletion in cardiomyocytes. All mtDNA genes are essential for the biogenesis and function of mitochondria, so mutations leading to altered overall gene expression would be expected to cause a deficiency in energy metabolism and enhanced production of ROS, leading to oxidative stress (40).

Alterations in proteins that affect ROS generation and oxidative stress may also enhance RIHD. Manganese superoxide dismutase (MnSOD), a mitochondrial matrix enzyme that protects against oxidative stress by converting superoxide to $\mathrm{H}_{2} \mathrm{O}_{2}$, can decrease cardiac injury severity. Mice deficient in MnSOD died within the first 10 days of life and exhibited dilated cardiomyopathy, among other abnormalities. A study by Nojiri et al. generated cardiac-specific MnSOD-deficient mice, and these mice developed congestive heart failure with severe cardiac muscle degeneration and significantly reduced ATP production, demonstrating that alterations in enzymes important for maintenance of ROS levels can lead to oxidative stressdependent heart disease (52). Other studies have shown that MnSOD can play an important role in ischemia-reperfusion cardiac injury as well (52).

G protein-coupled receptor kinase (GRK) is another protein reported to regulate ROS in response to stress. Studies have shown data that GRK may act both a protector against and a promotor for death following ischemic injury (45,
53). Removal of cardiac-specific GRK2 has been linked to embryonic cardiovascular development, adult cardiac dilatation, early atherosclerosis and inhibited angiogenesis in mice (42, 54-57). Franco et al. evaluated cell cultures with knockdown or overexpressed GRK2 3-8h after exposure of a single dose of $4 \mathrm{~Gy}$. Knockdown of GRK caused morphologic mitochondrial changes, reduced membrane potential and reduced mitochondrial function (42). The overexpression of GRK2 protected mitochondria from radiation damage (42). Furthermore, it was demonstrated that in the presence of heat shock proteins, GRK2 interacts with mitofusins (MFN-1 and MFN-2), key regulators of mitochondrial fission and fusion (42, 58). Additional studies are required to understand the chronic response of GRK to radiation, but GRK-related pathways may be important targets to drive mitochondrial protection from radiation-induced damage.

Several other studies have noted radiation-induced mitochondrial changes in terms of oxidative stress and respiratory capacity in mice (34). These changes have been noted $\mathrm{h}$ to months following radiation exposure. Five and $24 \mathrm{~h}$ after $3 \mathrm{~Gy}$ total body irradiation, C57BL/6 mice had immediate changes in cardiac structure and function. On murine cardiac tissue proteomic analysis, mitochondrial proteins represented the protein class most sensitive to radiation, with increased levels of proteins involved in oxidative phosphorylation, including ATP synthase, NADH dehydrogenase and cytochrome $c$ oxidase (34).

Chronic low dose exposure of ionizing radiation can cause heart disease, as noted in atomic bomb survivors and nuclear power industry workers $(3,4,59)$. As previously mentioned, 
TABLE 1 | Summary of studies investigating the role of mitochondria in RIHD.

\begin{tabular}{|c|c|c|c|c|}
\hline References & Tissue type/Study subject & Methods/intervention & Radiation & Result \\
\hline Burch et al. (31) & in vivo; human cardiomyocyte & $\begin{array}{l}\text { Electron microscopy of irradiated } \\
\text { tissue of mediastinum }\end{array}$ & $\begin{array}{l}52 \text { Gy, unknown } \\
\text { fractionation }\end{array}$ & $\begin{array}{l}\text { Mito swollen; reduced and disorganized } \\
\text { cristae; fused double membrane }\end{array}$ \\
\hline Khan (32) & in vivo; rabbit myocardial cells & $\begin{array}{l}\text { Electron microscopy of irradiated } \\
\text { heart tissue }\end{array}$ & $\begin{array}{l}10 \text { or } 13 \mathrm{~Gy} \text {, single } \\
\text { dose }\end{array}$ & $\begin{array}{l}\text { Altered mito structure } 48 \mathrm{~h} \text { post-RT } \\
\text { exposure }\end{array}$ \\
\hline Prithivirajsingh et al. (33) & $\begin{array}{l}\text { in vitro; human cell lines } \\
\text { (dermal fibroblasts, AT, KSS, } \\
\text { DNA glioblastoma, and colon } \\
\text { carcinoma cell lines) }\end{array}$ & Evaluation of common deletion & $\begin{array}{l}\text { Cesium-137, } 4.17 \\
\text { Gy/min, total of } 5,10 \\
\text { or } 20 \text { Gy }\end{array}$ & $\begin{array}{l}\text { Increased levels of common deletion } 72 \mathrm{~h} \\
\text { post-RT; dose-independent }\end{array}$ \\
\hline Azimzadeh et al. (34) & $\begin{array}{l}\text { in vivo; C57BL/6 mice; } \\
\text { cardiac tissue protein lysates }\end{array}$ & $\begin{array}{l}\text { Proteomic analysis of irradiated } \\
\text { mito proteins }\end{array}$ & TBI, 3 Gy, single dose & $\begin{array}{l}5 \text { and } 24 \mathrm{~h} \text { post-RT-increased levels of } \\
\text { proteins involved in oxidative } \\
\text { phosphorylation (ATP synthase, NADH } \\
\text { dehydrogenase, cytochrome c oxidase) }\end{array}$ \\
\hline Barjaktarovic et al. (35) & $\begin{array}{l}\text { in vivo; C57BL/6N mice; } \\
\text { isolated cardiac mito }\end{array}$ & $\begin{array}{l}\text { Mito proteomic and functional } \\
\text { analysis of low dose RT localized to } \\
\text { heart ( } 4 \text { weeks) }\end{array}$ & 0.2 or 2 Gy, single dose & $\begin{array}{l}4 \text { weeks post-RT, } 2 \text { Gy (functional and } \\
\text { proteomic changes); } 0.2 \text { Gy functional } \\
\text { changes only) }\end{array}$ \\
\hline Barjaktaroic et al. (36) & $\begin{array}{l}\text { in vivo; C57BL/6N mice; } \\
\text { isolated cardiac mito }\end{array}$ & $\begin{array}{l}\text { Mito proteomic and functional } \\
\text { analysis of late effects ( } 40 \text { weeks) of } \\
\text { low dose RT localized to heart }\end{array}$ & 0.2 or 2 Gy, single dose & $\begin{array}{l}40 \text { weeks post-RT: } 2 \text { Gy (functional and } \\
\text { proteomic changes); } 0.2 \text { Gy (no significant } \\
\text { effect) }\end{array}$ \\
\hline Boerma et al. (37) & $\begin{array}{l}\text { in vivo; Gsta4-null vs. WT } \\
\text { mice; cardiac tissue }\end{array}$ & $\begin{array}{l}\text { Analysis of cardiac function and } \\
\text { proteomics following local heart RT }\end{array}$ & $18 \mathrm{~Gy}$, single dose & $\begin{array}{l}\text { Reduced CO, SV and EF in WT. Increased } \\
\text { levels of PGAM5 and Nrf2 in } \\
\text { Gsta4-null-mice }\end{array}$ \\
\hline Azimzadeh et al. (38) & $\begin{array}{l}\text { in vivo; C57BL/6 mice; } \\
\text { cardiac tissue protein lysates }\end{array}$ & $\begin{array}{l}\text { Analysis of PPAR- } \alpha \text { activity following } \\
\text { local radiation to the heart }\end{array}$ & 8 or 16 Gy, single dose & $\begin{array}{l}\text { PPAR- } \alpha \text { inactivated post-RT with } \\
\text { increased FFA, decreased mito complexes } \\
\text { I, III, V }\end{array}$ \\
\hline Azimzadeh et al. (4) & $\begin{array}{l}\text { in vivo; human } \\
\text { cardiomyocytes }\end{array}$ & $\begin{array}{l}\text { Epidemiologic proteomic analysis } \\
\text { following chronic occupational } \\
\text { exposures }\end{array}$ & $\begin{array}{l}100 \text { mcGy-5 Gy, } \\
\text { chronic exposure }\end{array}$ & $\begin{array}{l}\text { Dose-dependent increase phosphorylation } \\
\text { of PPAR- } \alpha \text { and decrease in mito complex I } \\
\text { and III and Nrf2 }\end{array}$ \\
\hline Salata et al. (39) & $\begin{array}{l}\text { Wistar rats; left ventricular } \\
\text { cardiac tissue }\end{array}$ & $\begin{array}{l}\text { Analysis of apoptotic factors } 5 \\
\text { months post-cardiac RT }\end{array}$ & 20 Gy, single dose & $\begin{array}{l}\text { Increased expression } \mathrm{Bax} / \mathrm{Bcl} 2 \text {, increased } \\
\text { apoptotic nuclei }\end{array}$ \\
\hline Sridharan et al. (40) & $\begin{array}{l}\text { Male Sprague-Dawley rats; } \\
\text { isolated left ventricular cardiac } \\
\text { mito }\end{array}$ & $\begin{array}{l}\text { Analysis of time course of RT mito } \\
\text { apoptotic changes (at } 2 \mathrm{~h}-9 \\
\text { months post-RT) }\end{array}$ & 3-21 Gy, single dose & $\begin{array}{l}\text { Bax/Bcl } 2 \text { ratio elevated ( } 6 \text { h- } 6 \text { months). } \\
\text { Apoptotic nuclei ( } 6 \text { and } 24 \mathrm{~h} \text { and } 2 \text { weeks) } \\
\text { Increased calcium-induced swelling/ MPT } \\
\text { susceptibility ( } 6 \text { h- } 9 \text { months) }\end{array}$ \\
\hline $\begin{array}{l}\text { Ferreira-Machado et al. } \\
\text { (41) }\end{array}$ & $\begin{array}{l}\text { Female Wistar rat } \\
\text { cardiomyocytes }\end{array}$ & $\begin{array}{l}\text { Analysis of caspase activity } 13 \\
\text { months post heart RT }\end{array}$ & 15 Gy, single dose & $\begin{array}{l}\text { Cleaved/activated caspase at } 13 \text { months } \\
\text { post-radiation }\end{array}$ \\
\hline Franco et al. (42) & HEK-293 cells & Analysis of GRK activity post-RT & 4 Gy, single dose & $\begin{array}{l}\text { Overexpression of GRK preserved mito } \\
\text { morphology, maintained membrane } \\
\text { potential and enhanced respiration }(3-8 \mathrm{~h} \\
\text { post-RT) }\end{array}$ \\
\hline
\end{tabular}

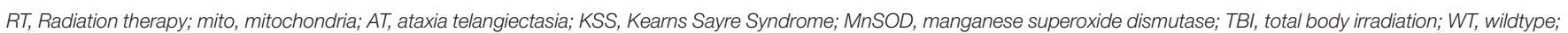
CO, cardiac output; SV, stroke volume; EF, ejection fraction; FFA, free fatty acids, MPT, membrane permeability transition; RT, radiation therapy.

doses as low as $0.1 \mathrm{~Gy}$ caused accumulation of the common deletion in human cell lines (51). However, other studies have shown minimal effect with these low doses. Barjaktarovic et al. studied $\mathrm{C} 57 \mathrm{BL} / 6 \mathrm{~N}$ mice that received either $0.2 \mathrm{~Gy}$, $2 \mathrm{~Gy}$ to the heart or sham radiation. Four weeks postexposure, cardiac mitochondria were examined for proteomic and functional alterations. After $2 \mathrm{~Gy}$, both functional and proteomic alterations were observed. Proteomic analysis revealed a total of 25 downregulated proteins, in three biological areas: oxidative phosphorylation, pyruvate metabolism and cytoskeletal structures. Functional impairment was reflected as partial deactivation of mitochondrial Complex I and III, decreased succinate-driven respiratory capacity, increased ROS levels and enhanced oxidation of mitochondrial proteins. At the lower dose $(0.2 \mathrm{~Gy})$, only proteomic changes were identified, suggesting a dose-dependence of mitochondrial dysfunction after cardiac radiation (35). This group then investigated the late cardiac effects at 40 weeks post-exposure, at which time respiratory capacity of the mitochondria was still reduced after $2 \mathrm{~Gy}$. This suggests that radiation can cause non-transient alterations of oxidative stress in mitochondria (36).

\section{GLUTATHIONE S-TRANSFERASE ALPHA 4 (GSTA4-4)/Nrf2 PATHWAY}

Another method of measuring oxidative stress is by quantifying downstream transcription factors. During the process of lipid peroxidation, 4-hydroxynonenal (4-HNE) concentrations 
increase, which directly activates nuclear factor erythroid 2 [NFE2]-related factor 2 (Nrf2, gene name NFE2L2), a transcription factor that targets a number of antioxidant proteins. Nrf2 is a redox-sensitive factor that controls oxidative responses within cells and has a role in endothelial function and cardiac protection $(22,60)$. The repressor protein Keap1 binds and sequesters Nrf2, promoting Nrf2 ubiquitin-mediated degradation. The protein phosphoglycerate mutase family member-5 (PGAM5) is attached to the mitochondrial membrane and can form a complex with Keap1 and Nrf2 $(37,61,62)$. Under oxidative conditions, Nrf2 is released from the complex, allowing nuclear accumulation of Nrf2 $(60,62)$. The role of Nrf2 was indirectly verified by the impact of glutathione S-transferase alpha 4 (GSTA4-4), which is an enzyme that removes 4-HNE. A study with Gsta4-null mice noted enhanced resistance to the cardiotoxic effects from doxorubicin, suggesting a compensatory mechanism may have caused cardiac protection (37). Boerma et al. conducted a similar study with the Gsta4-null mice with local heart irradiation to a total dose of $18 \mathrm{~Gy}$. Six months post-radiation exposure, the wildtype mice had reduced cardiac output, stroke volume and ejection fraction, with associated increased levels of cardiac troponinI levels when compared to the Gsta4-null mice. Additionally, the Gsta4-null mice had increased mRNA levels of PGAM5 and Nrf2. Nrf2 was also significantly elevated in the shamirradiated Gsta4-null mice when compared to wild-type mice. When comparing the levels of 14 different Nrf2 target genes, none were significantly elevated in wild-type irradiated mice; seven genes were significantly elevated in irradiated Gsta4-null mice compared to non-irradiated Gsta4-null mice, suggesting a stronger activation of the Nrf2 pathway in the irradiated Gsta4null mice (37).

Another study found that genes on rat chromosome 3 can alter RIHD by using consomic rat strains to identify genetic variants that cause differences in cardiac radiosensitivity. One week after $24 \mathrm{~Gy}$ of localized cardiac radiation, changes in expression of numerous gene pathways, including mitochondrial function, were seen between the sensitive and resistant rat hearts. Nrf2 was found to be an upstream regulator of many of the enriched pathways (61). Other preclinical investigations have studied the protective role of the $\mathrm{Nrf} 2$ pathway on radiation injury to cardiomyocytes and other cell lines, including embryonic fibroblasts and breast and lung epithelial cells (37). These results taken together suggest Nrf2 and GSTA-4 pathways may be promising targets for reducing mitochondrial dysfunction from cardiac radiation exposure.

\section{PEROXISOME PROLIFERATOR-ACTIVATED RECEPTOR- $\alpha$ (PPAR- $\alpha)$}

Cardiac muscle preferentially relies on fatty acid energy production via oxidative phosphorylation over glucose metabolism. Peroxisome proliferator-activated receptor- $\alpha$ $(\operatorname{PPAR}-\alpha)$ is a highly expressed transcription factor in tissues with elevated lipid metabolic turnover, including cardiac tissue. When PPAR- $\alpha$ is downregulated, lipid metabolism is impaired, as noted in PPAR- $\alpha$-null mice (38), suggesting PPAR- $\alpha$ regulates energy equilibrium. When $\mathrm{C} 57 \mathrm{BL} / 6$ mice were exposed to 8 or $16 \mathrm{~Gy}$ of cardiac radiation, PPAR- $\alpha$ was phosphorylated by ERK-MAPK causing decreased transcriptional activity, leading to increased free fatty acid levels and reduced levels of mitochondrial complexes I, III and V (38). The finding that radiation-induced PPAR- $\alpha$ alterations cause decreased expression of energy metabolism and mitochondrial respirationrelated genes has been corroborated in human subjects with chronic radiation exposure. In the 1940s, the Mayak Production Association built a nuclear facility in Russia, where workers were chronically exposed to incidental radiation during their occupational duties. Epidemiologic cohorts were analyzed to identify workers who died from heart disease and individual dosimetric monitors were used to determine radiation exposure. Studies in this cohort of individuals found significant increases in heart disease associated with total external gamma-ray doses, even after adjusting for confounding factors, such as smoking exposure (63-65). In a separate study, the protein expression from post-mortem heart samples were examined from a subset of workers exposed only to external gamma rays who had a diagnosis of ischemic heart disease and a primary cause of death of ischemic heart disease. Total doses of external exposure in this cohort ranged from $100 \mathrm{mcGy}$ to more than $5 \mathrm{~Gy}$. Proteomic analysis from 29 individuals identified a dose-dependent increase in phosphorylation of PPAR- $\alpha$ with a corresponding dose-dependent decrease in mitochondrial proteins, such as complexes I, III, and Nrf2 (4). PPAR- $\alpha$ has already shown an effect in other cardiovascular risk factors in preclinical and clinical studies (for dyslipidemia and diabetes mellitus) and is now an encouraging targetable agent for potential mitigation of RIHD $(6,66)$.

\section{MITOCHONDRIA AND APOPTOSIS}

Mitochondria are critical for some methods of programmed cell death, or apoptosis. For the intrinsic pathway, the inner and outer mitochondrial membranes must be permeabilized to release apoptotic factors, such as cytochrome $c$. The Bcl-2/Bax family of proteins help regulate and stabilize the membranes and govern the predilection for mitochondrial membrane permeabilization $(29,67)$. Once Bax is activated, it translocates from the cytoplasm to the mitochondrial membrane, where it can induce membrane permeability transition (MPT). MPT is characterized by mitochondrial swelling, depolarization of the membrane and uncoupled oxidative phosphorylation. It can also be induced by calcium influx and ROS. Radiation may also cause mitochondrial-mediated apoptosis due to the close association between the endoplasmic reticulum and mitochondria. When cardiomyocytes are irradiated, the endoplasmic reticulum releases a flux of excess calcium ions $\left(\mathrm{Ca}^{2+}\right)$ that facilitate permeabilization of mitochondria (29). Animal studies have shown increased levels of the $\mathrm{Bax} / \mathrm{Bcl} 2$ ratio expression following irradiation. In one analysis, increased expression levels of $\mathrm{Bax} / \mathrm{Bcl} 2$ and increased apoptotic nuclei were seen in Wistar rats 5 months after cardiac radiation $(20 \mathrm{~Gy})$, with an associated increase of fibrotic tissue and cardiomyocyte hypertrophy (39). Sridharan et al. investigated the time course of radiation-induced changes to mitochondria in rats sacrificed $2 \mathrm{~h}$ to 9 months 
following a single dose of radiation, ranging from 3 to $21 \mathrm{~Gy}$. Levels of Bax and $\mathrm{Bcl} 2$ were significantly increased by $6 \mathrm{~h}$ post-exposure. The $\mathrm{Bax} / \mathrm{Bcl} 2$ ratio was elevated from $6 \mathrm{~h}$ to 6 months after irradiation, but not significantly elevated at 9 months. These findings were associated with apoptotic nuclei at 6 and $24 \mathrm{~h}$ and 2 weeks following radiation (40). One study identified cleaved caspase 3, an apoptosis activator, as late as 13 months post local heart radiation (15 Gy) to Wistar rats $(40,41)$. Additionally, the study completed by Sridharan et al. noted increased radiation-induced susceptibility to MPT, measured by increased calcium-stimulated mitochondrial swelling. At time points ranging from $6 \mathrm{~h}$ to 9 months post-radiation, in a dosedependent manner, irradiated cardiac mitochondria were more susceptible to calcium-induced swelling. Previously, studies have noted only a transient depolarization of the mitochondrial membrane potential and MPT after radiation. This suggests that radiation may cause an enhancement in the susceptibility of MPT and pore opening in mitochondria to subsequent stressors (40).

\section{ENDOTHELIAL CELL MITOCHONDRIA}

Radiation exposure can induce endothelial cell activation, shifting endothelial cells into a pro-inflammatory state. When exposure is repeated or prolonged, the endothelium can alter its protective physiology, which can lead to exhaustion and a decrease in vascular function. This endothelial dysfunction leads to decreased vascular tone, inflammation and atherosclerosis, all of which may contribute to cardiovascular disease (28). Concentrations of mitochondria are relatively low in endothelial cells compared to cardiomyocytes and mitochondria produce a lower portion of total endothelial cell energy. However, endothelial cell mitochondria have been found to play important roles in cellular signaling (28). Radiation-induced endothelial cell mitochondrial dysfunction may contribute to RIHD, though data on this topic is currently limited. Endothelial cell functions that can be altered by radiation include $\mathrm{Ca}^{2+}$ regulation, apoptosis and oxidative stress signaling. Radiationinduced release of $\mathrm{Ca}^{2+}$ from the endoplasmic reticulum leads to increased mitochondrial $\mathrm{Ca}^{2+}$ uptake, yielding membrane swelling and release of apoptotic factors (29). However, $\mathrm{Ca}^{2+}$ plays numerous roles in signaling pathways and intracellular functions that theoretically may be affected by radiation (e.g., inner membrane calcium uniporter, mitochondrial $\mathrm{Ca}^{2+}$ activation of dehydrogenase enzymes and ATP synthase and TNF- $\alpha$-induced inflammation). These concepts have just begun to be addressed preclinically in the setting of radiation exposure (28).

Baselet et al. illustrated that dysregulation of the $\mathrm{Bcl} 2$ pathway (intrinsic apoptosis pathway) yields endothelial inflammation, apoptosis and senescence, all of which are coupled with atherosclerotic development (28). Along similar lines, cells can undergo senescence, the irreversible arrest of endothelial cell renewal, after extensive cell division or exposure to stressors, including radiation. Previous in vitro and in vivo studies have noted evidence of endothelial cell senescence following local radiation exposure. In human umbilical vein endothelial cells (HUVECs), mitochondrial membrane potential was altered 2 days after irradiation with $1.5,4$, and $10 \mathrm{~Gy}$. The membrane potential returned to baseline levels at days 5 and 6 with 1.5 and $4 \mathrm{~Gy}$, respectively; however, mitochondrial activity remained reduced in cells irradiated with $10 \mathrm{~Gy}$ (28). The underlying mechanisms of radiation-induced senescence are not fully established, though mechanisms may involving the p53-p21 and the IGF1-PI3K-Akt/mTOR pathways that may be attributable to the downregulation of Silent Information Regulator-1 (SIRT1) (68). SIRT1 is a NAD-dependent deacetylase that regulates many proteins involved in mitigating oxidative stress, and although its relationship to RIHD has not been explored, SIRT1-deficiency increased the sensitivity of thymocytes to apoptosis (69). Similar to cardiomyocytes, studies of in vitro endothelial cells noted increased production of ROS 24$72 \mathrm{~h}$ post-radiation exposure (5-20 Gy) (28). In addition, Nrf2 upregulation has also been implicated in oxidative stress-induced endothelial dysfunction $(1,28)$. Furthermore, proteomic data on $\mathrm{C} 57 \mathrm{BL} / 6$ mice receiving 8 or $16 \mathrm{~Gy}$ of local heart irradiation revealed expression of proteins associated with mitochondrial dysfunction within endothelial cells (70).

\section{CONCLUSION}

Radiation exposure to the thoracic region can cause a variety of cardiac injuries. Numerous preclinical animal and cell models have studied the mechanisms behind RIHD, though these are not yet fully elucidated. Here we have reviewed several factors related to radiation-induced cardiomyocyte and endothelial cell mitochondrial dysfunction, including mtDNA mutations, oxidative stress, alterations in various transcription factors and apoptosis. These factors ultimately play a role in the complex mitochondrial dynamics that can change the fate of cardiac cells. Through further understanding of mitochondriadependent mechanisms of RIHD, potential therapeutic targets can be developed to prevent and/or treat radiation-induced heart damage.

\section{AUTHOR CONTRIBUTIONS}

All authors contributed to conception and design of the review, wrote sections of the manuscript, contributed to manuscript revision, read, and approved the submitted version.

\section{FUNDING}

This work was supported by the Medical College of Wisconsin (MCW) Cancer Center and the Dr. Nancy Sobczak Fund for Breast Cancer (CB). Support was also received from NIH/NHLBI 1R01HL147884 (CB), the Mary Kay Foundation Grant No. 01729 (CB), a Susan G. Komen Grant \#CCR17483233 (CB), and the Michael H. Keelan, Jr., MD, Research Foundation Grant and the Cardiovascular Center at the Medical College of Wisconsin (CB).

\section{ACKNOWLEDGMENTS}

We apologize to the authors whose work was not cited due to space limitations. 


\section{REFERENCES}

1. Baselet B, Rombouts C, Benotmane AM, Baatout S, Aerts A. Cardiovascular diseases related to ionizing radiation: the risk of low-dose exposure (Review). Int J Mol Med. (2016) 38:1623-41. doi: 10.3892/ijmm.2016.2777

2. Stewart FA. Mechanisms and dose-response relationships for radiation-induced cardiovascular disease. Ann ICRP. (2012) 41:72-9. doi: 10.1016/j.icrp.2012.06.031

3. Howe GR, Zablotska LB, Fix JJ, Egel J, Buchanan J. Analysis of the mortality experience amongst U.S. nuclear power industry workers after chronic low-dose exposure to ionizing radiation. Radiat Res. (2004) 162:517-26. doi: $10.1667 /$ RR3258

4. Azimzadeh O, Azizova T, Merl-Pham J, Subramanian V, Bakshi MV, Moseeva $\mathrm{M}$, et al. A dose-dependent perturbation in cardiac energy metabolism is linked to radiation-induced ischemic heart disease in Mayak nuclear workers. Oncotarget. (2017) 8:9067-78. doi: 10.18632/oncotarget.10424

5. Stewart JR, Fajardo LF. Radiation-induced heart disease: an update. Prog Cardiovasc Dis. (1984) 27:173-94. doi: 10.1016/0033-0620(84)90003-3

6. Tapio S. Pathology and biology of radiation-induced cardiac disease. J Radiat Res. (2016) 57:439-48. doi: 10.1093/jrr/rrw064

7. Darby SC, Ewertz M, McGale P, Bennet AM, Blom-Goldman U, Bronnum D, et al. Risk of ischemic heart disease in women after radiotherapy for breast cancer. N Engl J Med. (2013) 368:987-98. doi: 10.1056/NEJMoa1209825

8. Haque W, Verma V, Fakhreddine M, Butler EB, Teh BS, Simone CB II. Trends in cardiac mortality in patients with locally advanced nonsmall cell lung cancer. Int J Radiat Oncol Biol Phys. (2018) 100:470-7. doi: 10.1016/j.ijrobp.2017.10.031

9. Wang K, Pearlstein KA, Patchett ND, Deal AM, Mavroidis P, Jensen BC, et al. Heart dosimetric analysis of three types of cardiac toxicity in patients treated on dose-escalation trials for Stage III non-small-cell lung cancer. Radiother Oncol. (2017) 125:293-300. doi: 10.1016/j.radonc.2017.10.001

10. Speirs CK, DeWees TA, Rehman S, Molotievschi A, Velez MA, Mullen D, et al. Heart dose is an independent dosimetric predictor of overall survival in locally advanced non-small cell lung cancer. J Thorac Oncol. (2017) 12:293-301. doi: 10.1016/j.jtho.2016.09.134

11. Yegya-Raman N, Wang K, Kim S, Reyhan M, Deek MP, Sayan M, et al. Dosimetric predictors of symptomatic cardiac events after conventionaldose chemoradiation therapy for inoperable NSCLC. J Thorac Oncol. (2018) 13:1508-18. doi: 10.1016/j.jtho.2018.05.028

12. Dess RT, Sun Y, Matuszak MM, Sun G, Soni PD, Bazzi L, et al. Cardiac events after radiation therapy: combined analysis of prospective multicenter trials for locally advanced non-small-cell lung cancer. J Clin Oncol. (2017) 35:1395-402. doi: 10.1200/JCO.2016.71.6142

13. Bradley JD, Paulus R, Komaki R, Masters G, Blumenschein G, Schild S, et al. Standard-dose versus high-dose conformal radiotherapy with concurrent and consolidation carboplatin plus paclitaxel with or without cetuximab for patients with stage IIIA or IIIB non-small-cell lung cancer (RTOG 0617): a randomised, two-by-two factorial phase 3 study. Lancet Oncol. (2015) 16:187-99. doi: 10.1016/S1470-2045(14)71207-0

14. Mulrooney DA, Yeazel MW, Kawashima T, Mertens AC, Mitby P, Stovall M, et al. Cardiac outcomes in a cohort of adult survivors of childhood and adolescent cancer: retrospective analysis of the Childhood Cancer Survivor Study cohort. BMJ. (2009) 339:b4606. doi: 10.1136/bmj.b4606

15. Haddy N, Diallo S, El-Fayech C, Schwartz B, Pein F, Hawkins M, et al. Cardiac diseases following childhood cancer treatment: cohort study. Circulation. (2016) 133:31-8. doi: 10.1161/CIRCULATIONAHA.115.016686

16. Bergom C, Currey A, Desai N, Tai A, Strauss JB. Deep inspiration breath hold: techniques and advantages for cardiac sparing during breast cancer irradiation. Front Oncol. (2018) 8:87. doi: 10.3389/fonc.2018.00087

17. Bergom C, Kelly T, Morrow N, Wilson JF, Walker A, Xiang Q, et al. Prone whole-breast irradiation using three-dimensional conformal radiotherapy in women undergoing breast conservation for early disease yields high rates of excellent to good cosmetic outcomes in patients with large and/or pendulous breasts. Int J Radiat Oncol Biol Phys. (2012) 83:821-8. doi: 10.1016/j.ijrobp.2011.08.020

18. Bradley JA, Mendenhall NP. Novel radiotherapy techniques for breast cancer. Annu Rev Med. (2018) 69:277-88. doi: 10.1146/annurev-med-042716-103422
19. Modiri A, Sabouri P, Gu X, Timmerman R, Sawant A. Inversedplanned respiratory phase gating in lung conformal radiation therapy. Int J Radiat Oncol Biol Phys. (2017) 99:317-24. doi: 10.1016/j.ijrobp.2017. 05.039

20. Bernard ME, Glaser SM, Gill BS, Beriwal S, Heron DE, Luketich JD, et al. Results of a single institution experience with dose-escalated chemoradiation for locally advanced unresectable non-small cell lung cancer. Front Oncol. (2017) 7:1. doi: 10.3389/fonc.2017.00001

21. Ehrbar S, Perrin R, Peroni M, Bernatowicz K, Parkel T, Pytko I, et al. Respiratory motion-management in stereotactic body radiation therapy for lung cancer - a dosimetric comparison in an anthropomorphic lung phantom (LuCa). Radiother Oncol. (2016) 121:328-34. doi: 10.1016/j.radonc.2016.10.011

22. Boerma M, Sridharan V, Mao XW, Nelson GA, Cheema AK, Koturbash I, et al. Effects of ionizing radiation on the heart. Mutat Res. (2016) 770:319-27. doi: 10.1016/j.mrrev.2016.07.003

23. Vos J, Aarnoudse MW, Dijk F, Lamberts HB. On the cellular origin and development of atheromatous plaques. A light and electron microscopic study of combined X-ray and hypercholesterolemia-induced atheromatosis in the carotid artery of the rabbit. Virchows Arch B Cell Pathol Incl Mol Pathol. (1983) 43:1-16. doi: 10.1007/BF02932938

24. Ellulu MS, Patimah I, Khaza'ai H, Rahmat A, Abed Y, Ali F. Atherosclerotic cardiovascular disease: a review of initiators and protective factors. Inflammopharmacology. (2016) 24:1-10. doi: 10.1007/s10787-015-0255-y

25. Hoving S, Heeneman S, Gijbels MJ, te Poele JA, Russell NS, Daemen MJ, et al. Single-dose and fractionated irradiation promote initiation and progression of atherosclerosis and induce an inflammatory plaque phenotype in ApoE(-/-) mice. Int J Radiat Oncol Biol Phys. (2008) 71:848-57. doi: 10.1016/j.ijrobp.2008.02.031

26. Stewart FA, Heeneman S, Te Poele J, Kruse J, Russell NS, Gijbels M, et al. Ionizing radiation accelerates the development of atherosclerotic lesions in ApoE-/- mice and predisposes to an inflammatory plaque phenotype prone to hemorrhage. Am J Pathol. (2006) 168:649-58. doi: 10.2353/ajpath.2006.050409

27. Boerma M, Hauer-Jensen M. Preclinical research into basic mechanisms of radiation-induced heart disease. Cardiol Res Pract. (2010) 2011:858262. doi: $10.4061 / 2011 / 858262$

28. Baselet B, Sonveaux P, Baatout S, Aerts A. Pathological effects of ionizing radiation: endothelial activation and dysfunction. Cell Mol Life Sci. (2019) 76:699-728. doi: 10.1007/s00018-018-2956-Z

29. Wang H, Wei J, Zheng Q, Meng L, Xin Y, Yin X, et al. Radiation-induced heart disease: a review of classification, mechanism and prevention. Int J Biol Sci. (2019) 15:2128-38. doi: 10.7150/ijbs.35460

30. Koleini N, Kardami E. Autophagy and mitophagy in the context of doxorubicin-induced cardiotoxicity. Oncotarget. (2017) 8:46663-80. doi: 10.18632/oncotarget.16944

31. Burch GE, Sohal RS, Sun SC, Miller GC, Colcolough HL. Effects of radiation on the human heart. An electron microscopic study. Arch Intern Med. (1968) 121:230-4. doi: 10.1001/archinte.1968.03640030022003

32. Khan MY. Radiation-induced cardiomyopathy: an electron microscopic study of cardiac muscle cells. Am J Pathol. (1973) 73:131-46.

33. Prithivirajsingh S, Story MD, Bergh SA, Geara FB, Ang KK, Ismail $\mathrm{SM}$, et al. Accumulation of the common mitochondrial DNA deletion induced by ionizing radiation. FEBS Lett. (2004) 571:227-32. doi: 10.1016/j.febslet.2004.06.078

34. Azimzadeh O, Scherthan H, Sarioglu H, Barjaktarovic Z, Conrad M, Vogt A, et al. Rapid proteomic remodeling of cardiac tissue caused by total body ionizing radiation. Proteomics. (2011) 11:3299-311. doi: $10.1002 /$ pmic. 201100178

35. Barjaktarovic Z, Schmaltz D, Shyla A, Azimzadeh O, Schulz S, Haagen J, et al. Radiation-induced signaling results in mitochondrial impairment in mouse heart at 4 weeks after exposure to X-rays. PLoS ONE. (2011) 6:e27811. doi: 10.1371/journal.pone.0027811

36. Barjaktarovic Z, Shyla A, Azimzadeh O, Schulz S, Haagen J, Dorr W, et al. Ionising radiation induces persistent alterations in the cardiac mitochondrial function of C57BL/6 mice 40 weeks after local heart exposure. Radiother Oncol. (2013) 106:404-10. doi: 10.1016/j.radonc.2013.01.017 
37. Boerma M, Singh P, Sridharan V, Tripathi P, Sharma S, Singh SP. Effects of local heart irradiation in a glutathione S-transferase alpha 4-null mouse model. Radiat Res. (2015) 183:610-9. doi: 10.1667/RR13979.1

38. Azimzadeh O, Sievert W, Sarioglu H, Yentrapalli R, Barjaktarovic Z, Sriharshan A, et al. PPAR alpha: a novel radiation target in locally exposed Mus musculus heart revealed by quantitative proteomics. J Proteome Res. (2013) 12:2700-14. doi: 10.1021/pr400071g

39. Salata C, Ferreira-Machado SC, De Andrade CB, Mencalha AL, MandarimDe-Lacerda CA, de Almeida CE. Apoptosis induction of cardiomyocytes and subsequent fibrosis after irradiation and neoadjuvant chemotherapy. Int $J$ Radiat Biol. (2014) 90:284-90. doi: 10.3109/09553002.2014.887869

40. Sridharan V, Aykin-Burns N, Tripathi P, Krager KJ, Sharma SK, Moros EG, et al. Radiation-induced alterations in mitochondria of the rat heart. Radiat Res. (2014) 181:324-34. doi: 10.1667/RR13452.1

41. Ferreira-Machado SC, Salata C, Rocha NN, Correa AF, Corte-Real S, Peregrino AA, et al. Caspase-3 activation and increased procollagen type I in irradiated hearts. An Acad Bras Cienc. (2013) 85:215-22. doi: 10.1590/S0001-37652013005000009

42. Franco A, Sorriento D, Gambardella J, Pacelli R, Prevete N, Procaccini C, et al. GRK2 moderates the acute mitochondrial damage to ionizing radiation exposure by promoting mitochondrial fission/fusion. Cell Death Discov. (2018) 4:25. doi: 10.1038/s41420-018-0028-7

43. Piquereau J, Caffin F, Novotova M, Lemaire C, Veksler V, Garnier A, et al. Mitochondrial dynamics in the adult cardiomyocytes: which roles for a highly specialized cell? Front Physiol. (2013) 4:102. doi: 10.3389/fphys.2013.00102

44. Barth E, Stammler G, Speiser B, Schaper J. Ultrastructural quantitation of mitochondria and myofilaments in cardiac muscle from 10 different animal species including man. J Mol Cell Cardiol. (1992) 24:669-81. doi: 10.1016/0022-2828(92)93381-S

45. Franco A, Ciccarelli M, Sorriento D, Napolitano L, Fiordelisi A, Trimarco B, et al. Rays sting: the acute cellular effects of ionizing radiation exposure. Transl Med UniSa. (2016) 14:42-53.

46. Youle RJ, van der Bliek AM. Mitochondrial fission, fusion, and stress. Science. (2012) 337:1062-5. doi: 10.1126/science.1219855

47. Ljungman M, Hanawalt PC. Efficient protection against oxidative DNA damage in chromatin. Mol Carcinog. (1992) 5:264-9. doi: $10.1002 / \mathrm{mc} .2940050406$

48. Wang L, Kuwahara Y, Li L, Baba T, Shin RW, Ohkubo Y, et al. Analysis of Common Deletion (CD) and a novel deletion of mitochondrial DNA induced by ionizing radiation. Int J Radiat Biol. (2007) 83:433-42. doi: 10.1080/09553000701370878

49. Richard SM, Bailliet G, Paez GL, Bianchi MS, Peltomaki P, Bianchi NO. Nuclear and mitochondrial genome instability in human breast cancer. Cancer Res. (2000) 60:4231-7.

50. Lin PH, Lee SH, Su CP, Wei YH. Oxidative damage to mitochondrial DNA in atrial muscle of patients with atrial fibrillation. Free Radic Biol Med. (2003) 35:1310-8. doi: 10.1016/j.freeradbiomed.2003.07.002

51. Schilling-Toth B, Sandor N, Kis E, Kadhim M, Safrany G, Hegyesi H. Analysis of the common deletions in the mitochondrial DNA is a sensitive biomarker detecting direct and non-targeted cellular effects of low dose ionizing radiation. Mutat Res. (2011) 716:33-9. doi: 10.1016/j.mrfmmm.2011. 07.018

52. Nojiri H, Shimizu T, Funakoshi M, Yamaguchi O, Zhou H, Kawakami S, et al. Oxidative stress causes heart failure with impaired mitochondrial respiration. J Biol Chem. (2006) 281:33789-801. doi: 10.1074/jbc.M602118200

53. Sorriento D, Ciccarelli M, Santulli G, Illario M, Trimarco B, Iaccarino G. Trafficking GRK2: cellular and metabolic consequences of GRK2 subcellular localization. Transl Med UniSa. (2014) 10:3-7.

54. Matkovich SJ, Diwan A, Klanke JL, Hammer DJ, Marreez Y, Odley AM, et al. Cardiac-specific ablation of G-protein receptor kinase 2 redefines its roles in heart development and beta-adrenergic signaling. Circ Res. (2006) 99:996-1003. doi: 10.1161/01.RES.0000247932.71270.2c

55. Jaber M, Koch WJ, Rockman H, Smith B, Bond RA, Sulik KK, et al. Essential role of beta-adrenergic receptor kinase 1 in cardiac development and function. Proc Natl Acad Sci USA. (1996) 93:12974-9. doi: 10.1073/pnas.93.23.12974
56. Ciccarelli M, Sorriento D, Franco A, Fusco A, Del Giudice C, Annunziata $\mathrm{R}$, et al. Endothelial G protein-coupled receptor kinase 2 regulates vascular homeostasis through the control of free radical oxygen species. Arterioscler Thromb Vasc Biol. (2013) 33:2415-24. doi: 10.1161/ATVBAHA.113.3 02262

57. Rivas V, Carmona R, Munoz-Chapuli R, Mendiola M, Nogues L, Reglero $\mathrm{C}$, et al. Developmental and tumoral vascularization is regulated by $\mathrm{G}$ protein-coupled receptor kinase 2. J Clin Invest. (2013) 123:4714-30. doi: $10.1172 /$ JCI67333

58. Sorriento D, Gambardella J, Fiordelisi A, Iaccarino G, Illario M. GRKs and beta-arrestins: "Gatekeepers" of mitochondrial function in the failing heart. Front Pharmacol. (2019) 10:64. doi: 10.3389/fphar.2019. 00064

59. Little MP. Cancer and non-cancer effects in Japanese atomic bomb survivors. J Radiol Prot. (2009) 29:A43-59. doi: 10.1088/0952-4746/29/2A/S04

60. Holmstrom KM, Kostov RV, Dinkova-Kostova AT. The multifaceted role of Nrf2 in mitochondrial function. Curr Opin Toxicol. (2016) 1:80-91. doi: 10.1016/j.cotox.2016.10.002

61. Schlaak RA, Frei A, Schottstaedt AM, Tsaih SW, Fish BL, Harmann L, et al. Mapping genetic modifiers of radiation-induced cardiotoxicity to rat chromosome 3. Am J Physiol Heart Circ Physiol. (2019) 316:H1267-80. doi: 10.1152/ajpheart.00482.2018

62. Kansanen E, Kuosmanen SM, Leinonen H, Levonen AL. The Keap1-Nrf2 pathway: mechanisms of activation and dysregulation in cancer. Redox Biol. (2013) 1:45-9. doi: 10.1016/j.redox.2012.10.001

63. Azizova TV, Grigoryeva ES, Haylock RG, Pikulina MV, Moseeva MB. Ischaemic heart disease incidence and mortality in an extended cohort of Mayak workers first employed in 1948-1982. Br J Radiol. (2015) 88:20150169. doi: 10.1259/bjr.20150169

64. Azizova TV, Muirhead CR, Druzhinina MB, Grigoryeva ES, Vlasenko EV, Sumina MV, et al. Cardiovascular diseases in the cohort of workers first employed at Mayak PA in 1948-1958. Radiat Res. (2010) 174:155-68. doi: $10.1667 / R R 1789.1$

65. Simonetto C, Azizova TV, Grigoryeva ES, Kaiser JC, Schollnberger H, Eidemuller M. Ischemic heart disease in workers at Mayak PA: latency of incidence risk after radiation exposure. PLoS ONE. (2014) 9:e96309. doi: 10.1371/journal.pone.0096309

66. Grygiel-Gorniak B. Peroxisome proliferator-activated receptors and their ligands: nutritional and clinical implications-a review. Nutr J. (2014) 13:17. doi: 10.1186/1475-2891-13-17

67. Kroemer G, Galluzzi L, Brenner C. Mitochondrial membrane permeabilization in cell death. Physiol Rev. (2007) 87:99-163. doi: 10.1152/physrev.00013.2006

68. Wang Y, Boerma M, Zhou D. Ionizing radiation-induced endothelial cell senescence and cardiovascular diseases. Radiat Res. (2016) 186:153-61. doi: 10.1667/RR14445.1

69. Tanno M, Kuno A, Horio Y, Miura T. Emerging beneficial roles of sirtuins in heart failure. Basic Res Cardiol. (2012) 107:273. doi: 10.1007/s00395-012-0273-5

70. Azimzadeh O, Sievert W, Sarioglu H, Merl-Pham J, Yentrapalli R, Bakshi MV, et al. Integrative proteomics and targeted transcriptomics analyses in cardiac endothelial cells unravel mechanisms of long-term radiation-induced vascular dysfunction. J Proteome Res. (2015) 14:1203-19. doi: 10.1021/pr501141b

Conflict of Interest: The authors declare that the research was conducted in the absence of any commercial or financial relationships that could be construed as a potential conflict of interest.

Copyright (c) 2020 Livingston, Schlaak, Puckett and Bergom. This is an open-access article distributed under the terms of the Creative Commons Attribution License (CC $B Y)$. The use, distribution or reproduction in other forums is permitted, provided the original author(s) and the copyright owner(s) are credited and that the original publication in this journal is cited, in accordance with accepted academic practice. No use, distribution or reproduction is permitted which does not comply with these terms. 